\title{
Article \\ Performance of Ni-Based Coatings with Various Additives Fabricated by Cold Gas Spraying
}

\author{
Ekaterina Alekseeva ${ }^{1, *}$, Margarita Shishkova ${ }^{1, *}$, Darya Strekalovskaya ${ }^{1}$, Nikita Shaposhnikov ${ }^{1}$, \\ Dmitry Gerashchenkov ${ }^{2}$ iD and Pavel Glukhov ${ }^{3}$
}

1 Scientific and Technological Complex "New Technologies and Materials", Institute of Advanced Engineering Technologies, Peter the Great Saint-Petersburg Polytechnic University, Polytechnicheskaya 29, 194064 St. Petersburg, Russia; strekal_da@spbstu.ru (D.S.); shaposhn_no@spbstu.ru (N.S.)

2 NRC "Kurchatov Institute"_CRISM “Prometey", 49 Shpalernaya str., 191015 St. Petersburg, Russia; gda.prometey@mail.ru

3 PAO "Severstal", Directorate of Technical Development and Quality, 30 Mira str., 162608 Cherepovets, Russia; pa.glukhov@severstal.com

* Correspondence: alekseeva_el@spbstu.ru (E.A.); shishkova_ml@spbstu.ru (M.S.); Tel.: +7-9112503477 (E.A.); +7-9523702485 (M.S.)

check for

updates

Citation: Alekseeva, E.; Shishkova,

M.; Strekalovskaya, D.; Shaposhnikov,

N.; Gerashchenkov, D.; Glukhov, P.

Performance of Ni-Based Coatings

with Various Additives Fabricated by

Cold Gas Spraying. Metals 2022, 12,

314. https://doi.org/10.3390/

met12020314

Academic Editors:

Mieczyslaw Scendo and

Pasquale Cavaliere

Received: 30 September 2021

Accepted: 5 February 2022

Published: 10 February 2022

Publisher's Note: MDPI stays neutral with regard to jurisdictional claims in published maps and institutional affiliations.

Copyright: (C) 2022 by the authors. Licensee MDPI, Basel, Switzerland. This article is an open access article distributed under the terms and conditions of the Creative Commons Attribution (CC BY) license (https:// creativecommons.org/licenses/by/ $4.0 /)$.

\begin{abstract}
The complexity of the operating conditions in oil fields requires the development and use of materials with unique properties. This paper presents the study results for nickel-based coatings fabricated by cold gas spraying. In this study, compositions based on $\mathrm{Ni}, \mathrm{Ni}-\mathrm{Cu}, \mathrm{Ni}-\mathrm{Zn}, \mathrm{Ni}-\mathrm{Al}_{2} \mathrm{O}_{3} / \mathrm{TiC}$ coatings applied to low-alloyed steel bases were investigated. Corrosion resistance was studied by means of electrochemical autoclave testing in simulated oilfield conditions. Hydroabrasive resistance was studied using a unique testing bench. Scanning electron microscopy mappings, microhardness testing, and adhesion testing were used to correlate the results of the tests with the structure, continuity, and porosity of the studied coatings. All the studied coating specimens had a sufficiently high adhesion. The Ni-Zn coating exhibited the lowest corrosion resistance and high hydroabrasive resistance. The $\mathrm{Ni}-\mathrm{Cu}$ coatings exhibited a high degree of corrosion. The $\mathrm{Al}_{2} \mathrm{O}_{3} / \mathrm{TiC}$ additives gave ambiguous results with respect to the studied properties. Thicknesses of 40-60 microns provided acceptable performance for the studied coatings. Thus, varying the chemical composition the thickness of coatings allows optimal qualities to be obtained for Ni-based coatings made by cold gas spraying for use in the oil and gas industry.
\end{abstract}

Keywords: Ni-coatings; composite coating; cold gas spraying; oil and gas industry; corrosion; coatings; cold spray coatings; protective coating; hydroabrasive resistance

\section{Introduction}

The aggressive conditions encountered in the oil and gas industry require corrosionresistant materials for service in chloride-containing media saturated with hydrogen sulfide and carbon dioxide aqueous solutions, and which contain abrasive particles [1,2]. However, corrosion-resistant steels and alloys are associated with significant capital costs and technical drawbacks; therefore, various types of coatings are becoming increasingly crucial for the oil and gas industry [2]. At this moment, nonmetallic polymer epoxy coatings are widely used for oilfield pipelines and tubing, and aluminum, zinc, and nickel coatings are used for tubing and more expensive downhole equipment, as well as for certain components like flanges and bolting [3].

The highly aggressive operating conditions require nickel coatings, since nickel provides corrosion resistance in a wide range of conditions, wear resistance, and heat resistance [4]. Various methods can be used to apply nickel-based coatings of various compositions, and the most widespread methods include electrochemical and chemical 
deposition [5,6], cladding [7,8], thermal spray methods [9-11], chemical vapor-deposited coating [12], and physical vapor deposition [13] methods.

Thermal spray methods allow coatings to be obtained with various compositions, controlled over the thickness of the coating. The method of cold gas dynamic spraying, or cold spraying (CS), is based on the formation of a strong metal layer when a two-phase supersonic flow hits a perpendicularly located surface. It is relatively economical, technologically straightforward, and ecologically friendly compared to the methods mentioned above, and therefore has been used in this work [14]. The cold gas dynamic spraying method has the following advantages:

- Particles are transferred in a "cold" [14,15] state with transfer rates of up to 2 Mach numbers and more;

- The heating of particles occurs due to the conversion of kinetic energy into thermal energy in the process of interaction with an obstacle, i.e., directly during the formation of the coating;

- The ability to obtain coatings that are entirely adequate in composition to the sprayed powder;

- The ability to obtain composite coatings with a constant and adjustable composition over the thickness of the coating;

- No negative thermal effects on the substrate material;

- Relative safety, process economy, and simplicity.

The limitation of this method is the use of preferentially ductile materials for the spraying and the fractional composition of no more than 60 microns, and a relatively low coefficient of use of powders (deposition efficiency) [15]. This technology has great potential in almost every field, and has found application in repair and restoration work, for the protection of welding seams, in the restoration of worn surfaces and cracks, for the metallization of ceramics, glasses and polymers, and for the generation of complex surfaces, as well as in biomedical and other applications [16-18].

The literature data show that the composition of coatings, the presence of additives, and the application modes significantly affect the properties of coatings. Therefore, there is evidence of increased wear resistance and corrosion resistance when copper is added to a nickel matrix [19,20]. Zinc additive provides a high level of adhesion and increased corrosion resistance [21,22]. In [23-26], the use of modifiers or composite coatings can improve the characteristics of nickel-based coatings. Nickel matrix reinforced with particles such as $\mathrm{Al}_{2} \mathrm{O}_{3}, \mathrm{SiC}, \mathrm{ZrO}_{2}, \mathrm{SiO}_{2}$, etc., of nanoscale or micron size enhances the corrosion resistance, wear resistance, and microhardness of steel [27-32].

Therefore, the purpose of this work is to study the effect of the chemical composition $\left(\mathrm{Ni}, \mathrm{Ni}-\mathrm{Cu}, \mathrm{Ni}-\mathrm{Zn}, \mathrm{Ni}-\mathrm{Al}_{2} \mathrm{O}_{3}, \mathrm{Ni}-\mathrm{TiC}\right)$ on the corrosion and wear resistance of nickel coatings obtained by the cold gas dynamic spraying (CS) method to assess their applicability in the oil and gas industry.

Previously, we have presented some results of the investigation of the nickel-based CS coatings in a conference paper [33]. Here, we focus on the technology of deposition and the effect of the initial powders and mixtures for spraying and assess the coatings in the modeled oil and gas media.

\section{Materials and Methods}

The deposition of the nickel coatings was performed using the method of cold gas dynamic spraying on a commercial "Dimet-403" installation (OZPN Ltd., Obninsk, Russia). This equipment is a mobile installation, with the help of which it is possible to carry out repair work under operational conditions. This may be especially relevant, for example, for the oil and gas industry. To obtain a uniform thickness of the coating on the surface of the substrate, a Kawasaki-FS 003 robot was used, on which the sputtering unit of the Dimet-403 installation was fixed. The robotic arm also provides a predetermined movement speed in the required interval. The distance from the spray nozzle exit was $10 \mathrm{~mm}$; the nozzle type was a Laval nozzle; the gas flow temperature was $460{ }^{\circ} \mathrm{C}$; particle velocity in the 
gas flow velocity was $620 \mathrm{~m} / \mathrm{s}$, which is an average particle velocity; and the gas flow velocity was analyzed by a laser Doppler velocity meter. The laser Doppler measurement method is based on the fact that the scattered radiation will have a frequency shift relative to the probe radiation, proportional to the speed of particle movement. The heterodyne measurement method is based on this method. For streams with velocities of 300-800 m/s, it is more rational to use direct optical detection of Doppler frequency shifts of the light scattered in the stream, based on the use of ultra-high-spectral-resolution devices (at a level of 107), making it possible to highlight the particle and "catch" the reflected signal. Since the particle is moving, the reflected signal will be shifted, and analysis of how much it is shifted will determine the velocity $[15,34]$.

Powder materials with a given chemical and fractional composition are used for spraying coatings by the CS method. To achieve high adhesion strength, the optimal choice of the substrate material and the method of surface preparation is used. When preparing the substrate for spraying, the surface was sandblasted to obtain a juvenile surface. Surface cleaning agents were used to degrease surface contamination with organic compounds.

The process of CS includes the following procedures: control of commercially produced gas-atomized powders for chemical and fractional composition using a laser diffraction particle size analyzer Malvern Zetasizer Nano-ZS and Malvern Mastersizer 2000 (Malvern Instruments Ltd., Worcestershire, UK); preparation of two types of composite powders-mechanical mixture and mechanically alloyed powder-on an IVCh-3 type attritor (REC "Mekhanobr-Tekhnika", JSC, Saint-Petersburg, Russia) installation; heat treatment of powder materials using an SNOL-30/1100 Muffle Furnace (Snol-Therm Ltd., Tver, Russia); sandblasting the surface of the substrate; applying a powder mixture to a substrate.

The coating was carried out on low-carbon steel plate specimens. Mechanical mixtures (the simplest option) and mechanically alloyed (to obtain a mechanically unified system in the volume of one powder particle) pure nickel and nickel powders with the addition of copper and zinc at various concentrations were used as powders for coating; the $\mathrm{Al}_{2} \mathrm{O}_{3}$ and $\mathrm{TiC}$ powders were used to modify the coatings. Corundum or other high-hardness powder acted as an abrasive: first, this prevents the powder from sticking in the nozzle that forms the flow; second, the high-hardness particles provide a constant treatment of the surface to be coated, thereby removing loosely adhered particles. Therefore, non-metallic particles play the role of an abrasive- they continuously clean the surface for the sprayed layer and ensure the compaction of the layers, due to which adhesion, cohesion and density of coatings are increased. At the same time, their content in the coating composition is small, and their relatively neutral chemical activity does not affect the corrosion resistance. The content of the aluminum oxide fraction in zinc and copper powders has been found to be up to $50 \%[30,31]$.

The main criteria for choosing the material of the reinforcing component were high microhardness, delivery of the required fraction, the ability to form a coherent bond with the matrix material, and low cost. Based on the above, corundum powder was selected as the material for the reinforcing component. It is worth noting that $\mathrm{Al}_{2} \mathrm{O}_{3}$ has a predominant fraction of 20-40 microns and, accordingly, acts as a "blasting" material, since it has a more significant fraction than the $\mathrm{TiC}$. The $\mathrm{TiC}$ has a finer fraction (0.5-1.5 microns). Therefore, it does not as effectively promote the development of the substrate surface compared to larger $\mathrm{Al}_{2} \mathrm{O}_{3}$; thus, its being built into the coating as a modifier provides hardening and more even distribution.

To manufacture the mechanically alloyed powders, the technology of processing a previously prepared mechanical mixture in a cup grinder was used. The mechanical mixture was made in a mixer for $1 \mathrm{~h}$. Before mixing, the powders were dried in an oven for $1 \mathrm{~h}$ at a temperature of $120^{\circ} \mathrm{C}$. The compositions and thicknesses of the applied coatings are given in Table 1. Basically, $90-10 \%$ and $60-40 \%$ ratios of elements were used (some extreme points are selected; in the future, it is planned to further optimize the compositions). Due to the powder size and application modes, the thickness varied from 30 to 200 microns. 
Table 1. Composition and thickness of the applied coatings.

\begin{tabular}{|c|c|c|}
\hline Sample & Chemical Composition, wt.\% & Thickness, $\pm 5 \mu \mathrm{m}$ \\
\hline Ni100 & $\mathrm{Ni}-100 \%$ & 30 \\
\hline Ni90-TiC10 & $\mathrm{Ni}-90 \%, \mathrm{TiC}-10 \%$ & 70 \\
\hline Ni60-TiC40 & $\mathrm{Ni}-60 \%, \mathrm{TiC}-40 \%$ & 70 \\
\hline $\mathrm{Ni} 60-\mathrm{Al}_{2} \mathrm{O}_{3} 40 / 60$ & $\mathrm{Ni}-60 \%, \mathrm{Al}_{2} \mathrm{O}_{3}-40 \%$ & 60 \\
\hline $\mathrm{Ni} 60-\mathrm{Al}_{2} \mathrm{O}_{3} 40 / 130$ & $\mathrm{Ni}-60 \%, \mathrm{Al}_{2} \mathrm{O}_{3}-40 \%$ & 130 \\
\hline Ni90-Cu10/40* & $\mathrm{Ni}-90 \%, \mathrm{Cu}-10 \%$ & 40 \\
\hline Ni90-Cu10/150 * & $\mathrm{Ni}-90 \%, \mathrm{Cu}-10 \%$ & 150 \\
\hline Ni60-Cu40/50 * & $\mathrm{Ni}-60 \%, \mathrm{Cu}-40 \%$ & 50 \\
\hline $\mathrm{Ni} 60-\mathrm{Cu} 40 / 120$ * & $\mathrm{Ni}-60 \%, \mathrm{Cu}-40 \%$ & 120 \\
\hline Ni90-Zn10/50* & $\mathrm{Ni}-90 \%, \mathrm{Zn}-10 \%$ & 50 \\
\hline $\mathrm{Ni90-Zn10/150*}$ & $\mathrm{Ni}-90 \%, \mathrm{Zn}-10 \%$ & 150 \\
\hline Ni60-Zn40/100* & $\mathrm{Ni}-60 \%, \mathrm{Zn}-40 \%$ & 100 \\
\hline Ni60-Zn40/200* & $\mathrm{Ni}-60 \%, \mathrm{Zn}-40 \%$ & 200 \\
\hline \multicolumn{3}{|c|}{ Mechanically Alloyed (MA) } \\
\hline (Ni50-Cu50)60-TiC40 (MA) * & $\mathrm{Ni}-50 \%, \mathrm{Cu}-50 \%$ & 30 \\
\hline $\mathrm{Ni} 50-\mathrm{Cu} 50(\mathrm{MA})$ * & $\mathrm{Ni}-50 \%, \mathrm{Cu}-50 \%$ & - \\
\hline Ni50-Zn50 (MA) * & $\mathrm{Ni}-50 \%, \mathrm{Cu}-50 \%$ & 30 \\
\hline
\end{tabular}

*: The original powders of zinc and copper contain $20 \%$ corundum with a fraction of 20 microns.

A pure nickel coating cannot be obtained with a high thickness because, as mentioned above, corundum provides the surface preparation in order to achieve the best adhesion of the powder mixture to the substrate.

A mixture of the composition Ni50-Cu50 (MA) was not obtained in this work, since the powders and the set of parameters were not adapted to each other. During the preparation of the mechanically alloyed mixture, substantial work hardening occurred, and the plastic properties of the copper powder decreased significantly. This does not happen with zinc, since zinc is a suitable plasticizer. Additionally, the powder used in this work was not subjected to heat treatment. It is possible that during heat treatment in a protective environment, the necessary properties of copper powder to obtain an MA mixture would be provided.

\subsection{Corrosion Tests}

Electrochemical corrosion tests were conducted in a three-electrode cell using a Versa stat potentiostat/galvanostat device in $\mathrm{NaCl} 3.0$ wt.\% $2.5 \mathrm{pH}$ solution. This solution was chosen to promote pitting on the nickel-based coatings. The platinum electrode and the saturated calomel electrode (SCE) were used as the counter electrode and the reference electrode, respectively. A potentiodynamic polarization test was carried out with a scan rate of $0.16 \mathrm{mV} \mathrm{s}^{-1}$. The essence of the methodology for calculating the theoretical corrosion rates was based on measuring the polarization resistance of the investigated coatings (working electrode), which makes it possible to calculate the corrosion rates of the test material. Theoretical corrosion rates were calculated using Tafel curves according to [35].

To assess the corrosion resistance of the nickel coatings under simulated operational conditions, the samples were tested in an autoclave in $5.0 \mathrm{wt} . \% \mathrm{NaCl}$ solution saturated with hydrogen sulfide $\left(\mathrm{P}_{\mathrm{H} 2 \mathrm{~S}}=1 \mathrm{MPa}\right)$ and nitrogen $\left(\mathrm{P}_{\mathrm{N} 2}=5 \mathrm{MPa}\right)$ at a temperature of $+80^{\circ} \mathrm{C}$ for $240 \mathrm{~h}$. The autoclave test method under simulated oil well conditions is described in detail in [36]. A gravimetric method was used to assess the corrosion rates. Before testing, the samples were weighed with an accuracy of up to $0.0001 \mathrm{~g}$. The samples' edges were insulated with an epoxy compound. Corrosion rate was determined as follows:

$$
\mathrm{CRs}=\left(m_{2}-m_{1}\right) /(S \cdot t)
$$

where $m_{1}$-the mass of the specimens before tests $(\mathrm{g}) ; m_{2}$ - the mass of the specimens after tests $(\mathrm{g}) ; \mathrm{S}$-specimen's surface $\left(\mathrm{m}^{2}\right)$; $t$ - time of tests (hours). 
To assess the degradation of coatings, measurement of the adhesion value before and after tests by the pull-off strength method according to ASTM D4541 was used. To assess adhesion value, a metal "fungus" was glued to the prepared coated surface, after which the samples were kept for $24 \mathrm{~h}$ to polymerize the adhesive. Then, along the perimeter of "the fungus", the coating was cut off to carry out a pull-off test. The pull-off tests were carried out on a tensile testing machine UM-10T (USSR, modified in Saint-Petersburg, Russia) with a traverse speed of not more than $1 \mathrm{MPa} / \mathrm{s}$ for a pull-off time of no more than $90 \mathrm{~s}$. After tear-off, the nature of destruction was assessed.

\subsection{Hydroabrasive Testing}

The valuation of hydroabrasive wear was carried out on a laboratory test bench installation. The wear assessment was conducted using the gravimetric method according to the following formula:

$$
V=\frac{\Delta m}{t \cdot p}, \mathrm{~g} / \mathrm{cm}^{3},
$$

where $\Delta m$ is the weight loss of the samples during testing, $g$; $t$-time of tests (hours), $p$-density, $\mathrm{g} / \mathrm{cm}^{3}$.

The tests were carried out in water solution with 0.5 wt.\% quartz sand fraction 0.4-0.8 $\mathrm{mm}$. The testing process consisted of the following processes: the weighting of the test sample, preparation of the test solution by introducing abrasive particles into it, the supply of this solution to the surface of the sample in the submerged jet mode from a distance of $50 \mathrm{~mm}$ and at an angle of $90^{\circ}$ to a sample under constant circulation of the solution, weighing the sample after testing and evaluating the results. The diagram of the test stand is shown in Figure 1.

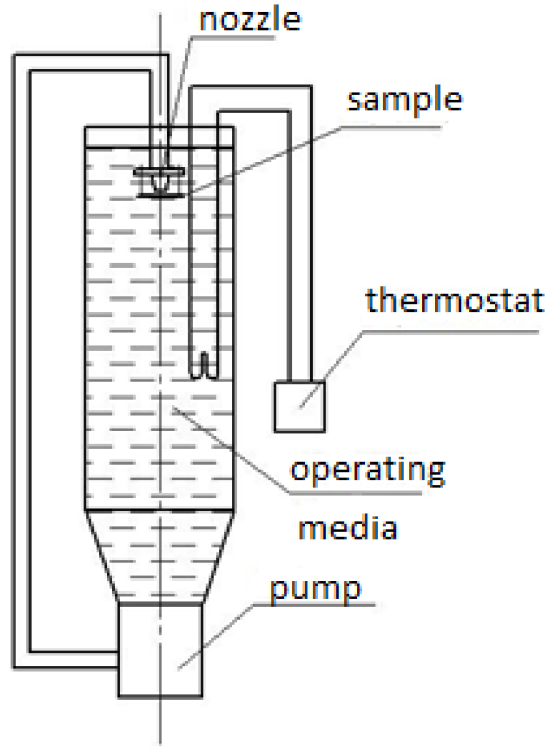

(a)

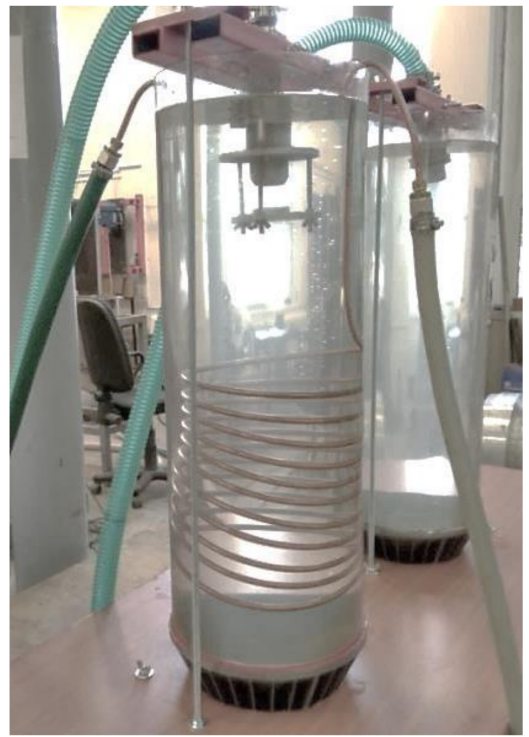

(b)

Figure 1. Stand for testing for hydroabrasive wear: (a) stand diagram; (b) general view of the hydroabrasive wear stand.

The testing method is described in detail in [36].

\subsection{Microstructure and Microhardness Investigation}

This work used modern methods for studying the structure and properties of powders and coatings. Scanning electron microscopy Tescan VEGA 3 (TESCAN ORSAY HOLDING, a.s., Brno, Czech Republic) equipped with Inca X-Max EDS analyzer (Oxford Instruments, 
Oxfordshire, UK) was used for the microstructure and chemical analyses of the studied coatings and powders. The microhardness was measured using a Vickers microhardness tester Reichert-Jung Micro-Duromat 4000 (Reichert-Jung Optische Werke, Austria) with a load of $50 \mathrm{~g}$ applied for $15 \mathrm{~s}$ and reported as the average of five different readings. The porosity was defined in accordance with ASTM STP947: the sample was immersed in a solution of potassium ferricyanide and sodium chloride, and kept for $5 \mathrm{~min}$ at a temperature of $18-30{ }^{\circ} \mathrm{C}$. The number of blue dots, corresponding to the number of pores, was counted on the controlled surface. Then, the average number of pores was calculated as the ratio of the number of pores to the area of the controlled surface:

$$
N_{a v}=\frac{N_{\text {summ }}}{F},
$$

where $N_{a v}$-the average number of pores per $\mathrm{cm}^{2}, N_{\text {summ }}$-total number of pores on the test surface, $F$-area, $\mathrm{cm}^{2}$.

\section{Results and Discussion}

\subsection{Characterization of Initial Powders}

Before using the initial powders for spraying, input control of the powder was performed: the fractional composition was determined and an energy dispersive analysis of nickel, copper and zinc powders, aluminum-corundum, and $\mathrm{TiC}$ was carried out.

In Ref. [16], it was proved that the dispersion of the powder required to obtain a high-quality coating was a rather important characteristic of the powder material used for spraying. A narrow range of particle size distribution increases the use rate of the powder and makes the process more productive.

The results of the fractional composition analysis are shown in Figure 2. The fractional composition of all the initial metal powders ranged from 20 microns to 60 microns, with a normal distribution, which meets the requirements for powders when spraying onto the "Dimet-403" installation.

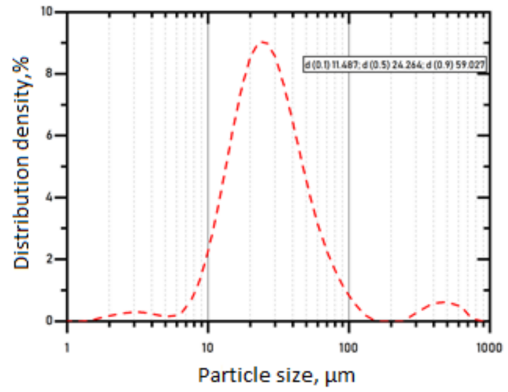

(a)

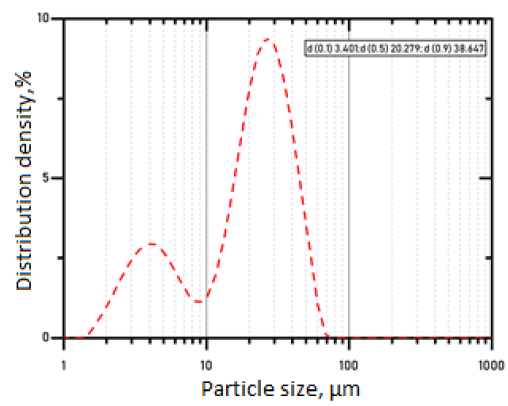

(c)

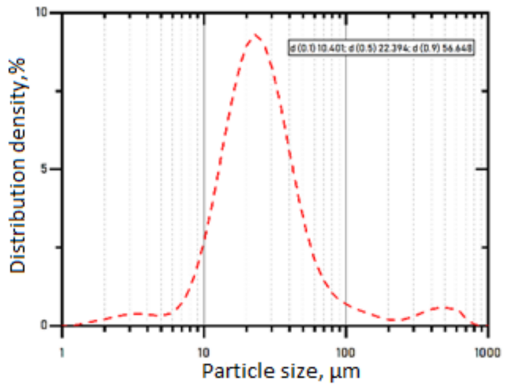

(b)

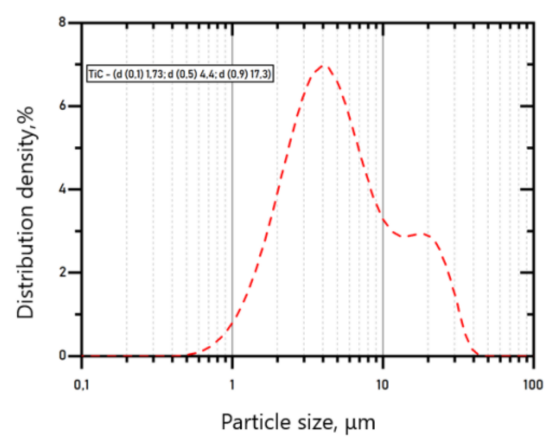

(d)

Figure 2. The results of the fractional composition study of the powders: (a) nickel; (b) copper; (c) zinc; (d) TiC. 
The nickel and copper powders mainly consist of particles ranging in diameter from 10 to 100 microns. The presence of two peaks for zinc powder particles in Figure $2 \mathrm{c}$ indicates that the composition consists of two main fractions of 4-5 microns for zinc and 20-40 microns for corundum. The fraction composition of the TiC powder looks like a doublet, which means that more than $70 \%$ of the powder is about $1-10$ microns, and $30 \%$ is from 10 to 50 microns, showing that titanium carbide powder has a main fraction of less than $5 \mu \mathrm{m}$, with the second peak at about $17 \mu \mathrm{m}$ most likely being an agglomerate of smaller particles. The absence of peaks in the region of more than $300 \mu \mathrm{m}$ indicates that the powders used did not form agglomerates. The use of such powders provides a basis for obtaining coatings with a uniform structure throughout the entire thickness of the coating.

The results of the energy dispersive analysis of the initial powders are shown in Figure 3.
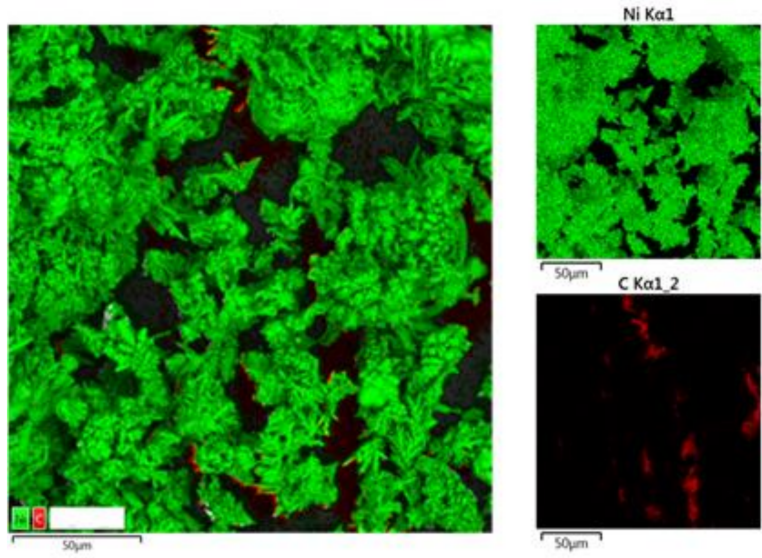

(a)
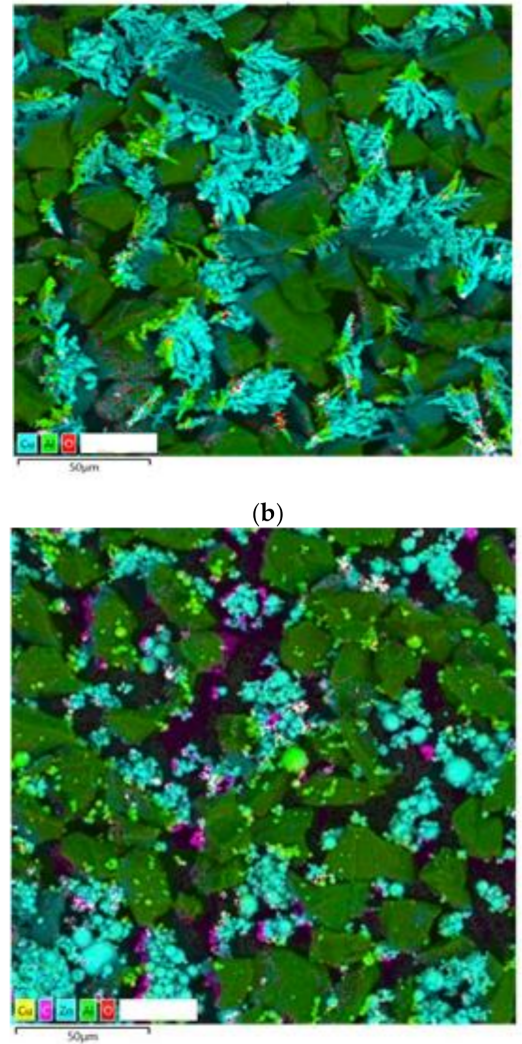

(c)

Figure 3. Cont. 


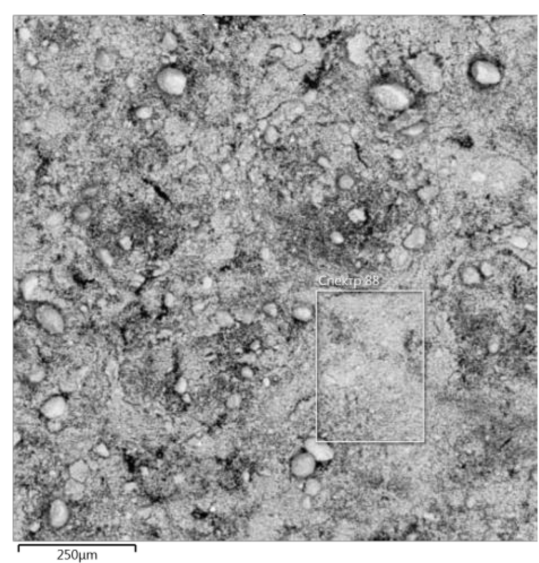

\begin{tabular}{ccc}
\hline Element & Line type & Mass,\% \\
\hline $\mathrm{Ti}$ & $\mathrm{K}$ & 96.76 \\
\hline $\mathrm{W}$ & $\mathrm{L}$ & 2.19 \\
\hline $\mathrm{Fe}$ & $\mathrm{K}$ & 0.44 \\
\hline $\mathrm{Co}$ & $\mathrm{K}$ & 0.26 \\
\hline $\mathrm{V}$ & $\mathrm{K}$ & 0.35 \\
\hline Summ & & 100 \\
\hline
\end{tabular}

This method cannot show carbon

(d)

Figure 3. The EDS map of the distribution of elements of (a) Ni powder; (b) Cu powder; and (c) $\mathrm{Zn}$ powder; and (d) X-ray fluorescence analysis results of the TiC powder.

The Ni powder presents a complex dendritic powder structure and does not contain any aluminum oxide additive. In contrast, $\mathrm{Zn}$ and $\mathrm{Cu}$ powder have rectangular-shaped aluminum oxide particles in the initial condition, while the TiC powder presents oval- and round-shaped particles, Figure 3.

Examples of the fraction composition of the powder mixtures (mechanical and mechanically alloyed) are given in Figure 4.

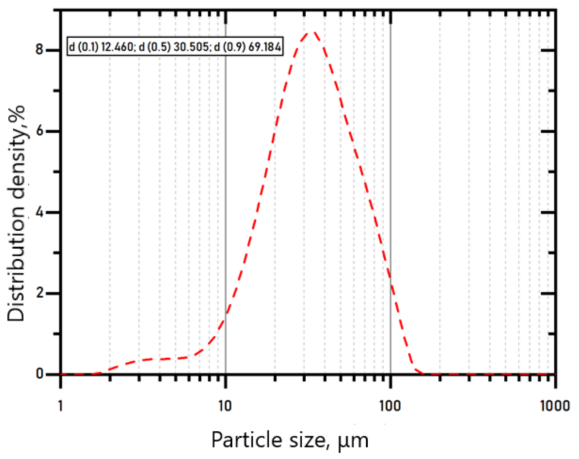

(a)

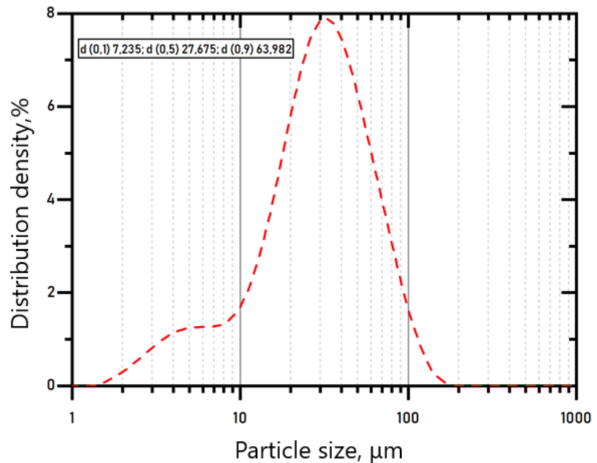

(b)

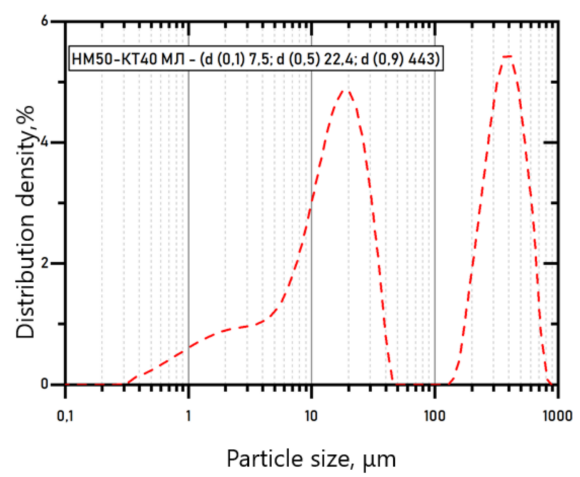

(c)

Figure 4. The results of the fractional composition study of the powders: (a) mechanical mixtures Ni60-Cu40, (b) mechanical mixtures Ni60-Zn40; (c) mechanically alloyed powder (Ni50-Cu50)60TiC40 (MA). 
The reaction content of the mechanical mixtures corresponds to the initial powders, Figure $4 \mathrm{a}, \mathrm{b}$. Figure $4 \mathrm{c}$ has two peaks, and the second peak in the region of $500 \mu \mathrm{m}$ is the result of the tendency to agglomerate the powder after mechanical alloying.

Powder Ni60-Zn40 (MA) and (Ni50-Cu50)60-TiC40 (MA) after mechanical alloying consist of particles that are mechanical connections of the initial components, see Figure 5.

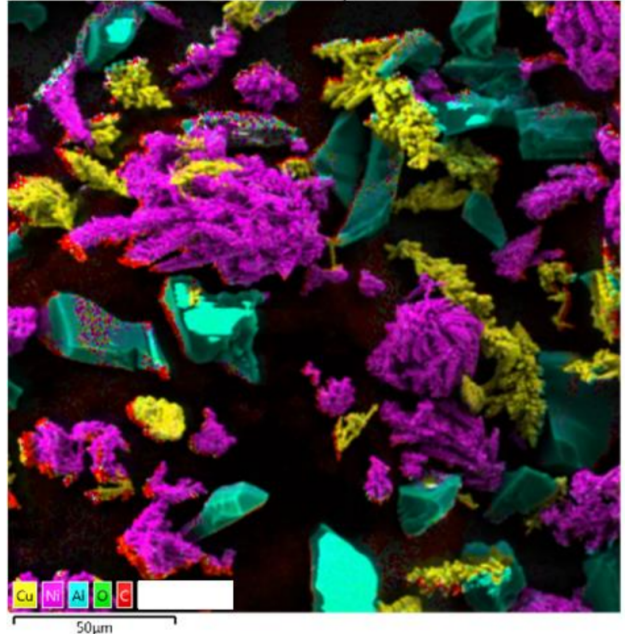

(a)

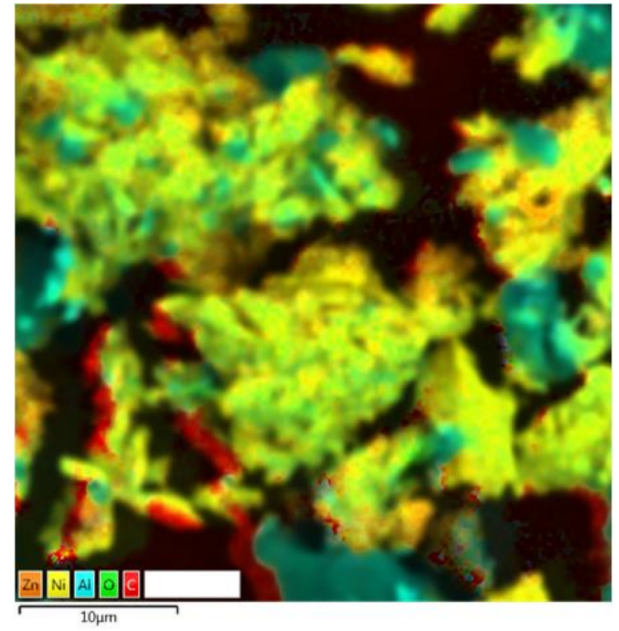

(c)

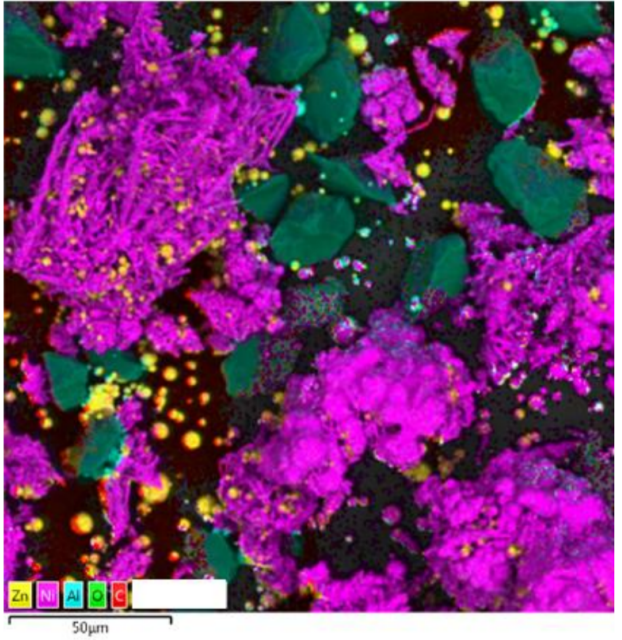

(b)

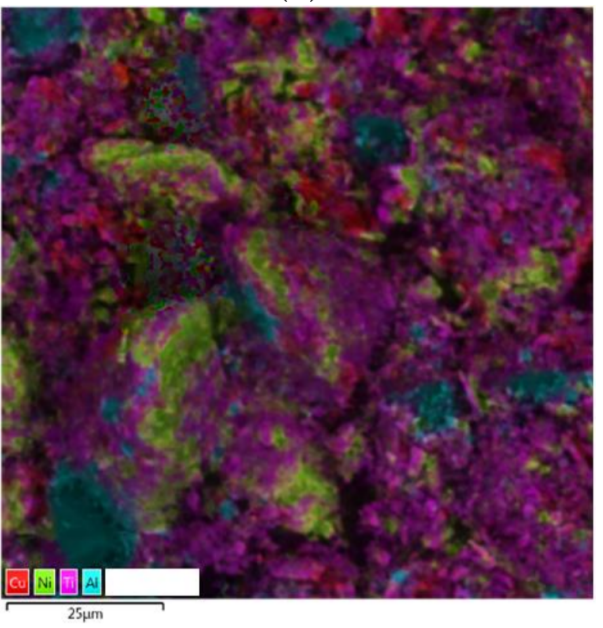

(d)

Figure 5. The EDS map of the distribution of elements of mechanical mixtures (a) Ni60-Cu40 and (b) Ni60-Zn40; and mechanically alloyed powders (c) Ni60-Zn40 (MA) and (d) (Ni50-Cu50)60-TiC40 (MA).

It can be seen that the powder obtained by mechanical alloying is a nickel matrix with zinc on its surface. The mechanically alloyed powder has an improved uniformity of structure compared to the mechanically mixed powder, in which the distribution of the elements is not uniform. The mechanical mixtures of nickel-zinc and nickel-copper did not exhibit agglomerates and consist of separate particles.

\subsection{Characterization of the Microstructure of Coatings}

The EDS analysis of the coatings made from the initial powder mixtures shows that the chemical and phase composition remained after spraying, and corresponded to the initial powder material. Figure 6 illustrates the structure of the Ni-Cu and Ni-Zn coatings with various element ratios. As can be seen in the image, the coatings have an even distribution of copper and zinc in the nickel matrix; there are some micro-discontinuities, but no cracks 
in the structures. The dark areas correspond to the corundum particles contained in the initial powders. Dark "islands" of $\mathrm{Al}_{2} \mathrm{O}_{3}$ with an average size of 2-5 microns are visible in the structures. This can be seen in the shades of the spectrum (aluminum and oxygen are indicated together on the energy dispersive spectrum map), and by size (size of the fraction of aluminum oxide) and shape (aluminum oxide has a fragmented form; pores, on the contrary, are usually round).

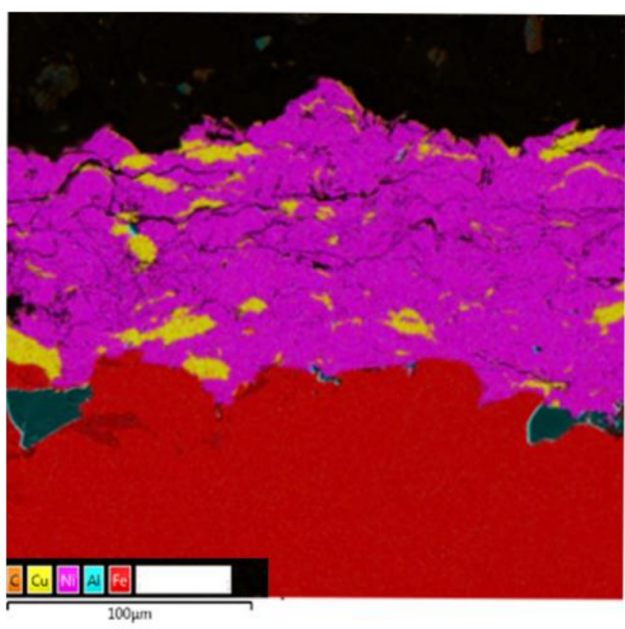

(a)

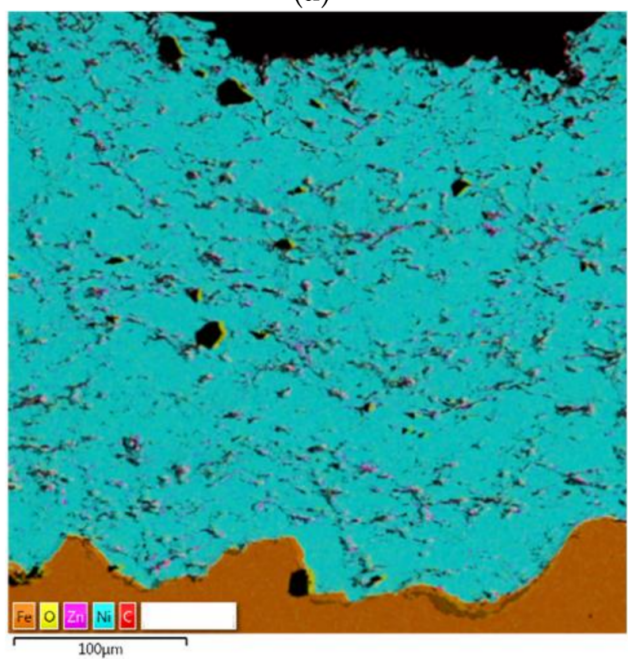

(c)

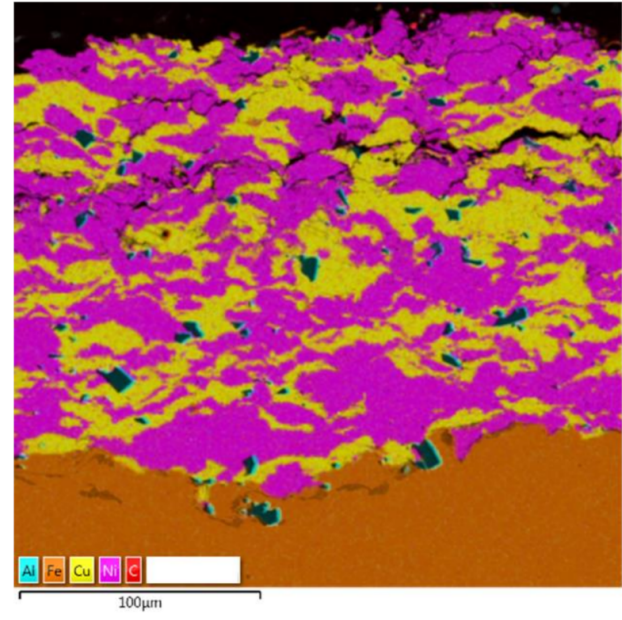

(b)

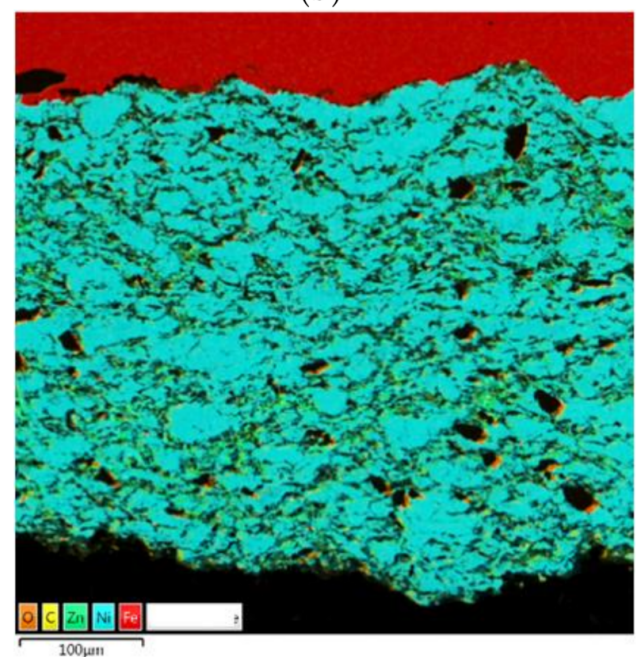

(d)

Figure 6. Ni-Zn and Ni-Cu-coatings: (a) Ni90-Cu10; (b) Ni60-Cu40; (c) Ni90-Zn10; (d) Ni60-Zn40.

Figure 6 shows that zinc, represented by the large dark areas, is evenly distributed in the coating, corresponding to the corundum particles in the initial powders. The distribution of copper in the coating corresponds to local formations with characteristic sizes corresponding to the fractional composition of the initial powder.

The microstructures of the Ni-Cu coatings exhibit cracks in the form of bundles, Figure $6 \mathrm{a}, \mathrm{b}$. The EDS analysis of the Ni-Cu coatings shows an uneven distribution of $\mathrm{Cu}$ in the nickel matrix. There are randomly distributed dark islands of $\mathrm{Al}_{2} \mathrm{O}_{3}$ in the matrix and in the Ni-Zn coatings and the pure Ni samples.

It can be seen from Figure $7 \mathrm{a}, \mathrm{b}$ that the $\mathrm{TiC}$ reinforcing particles in the Ni matrix are evenly distributed as separate particles and groups of several particles with sizes of up to 5 microns. It can be seen that mechanically alloyed powders (Figure $7 \mathrm{~b}$ ) are difficult to apply, appearing in the structure as separate layers with pores. 


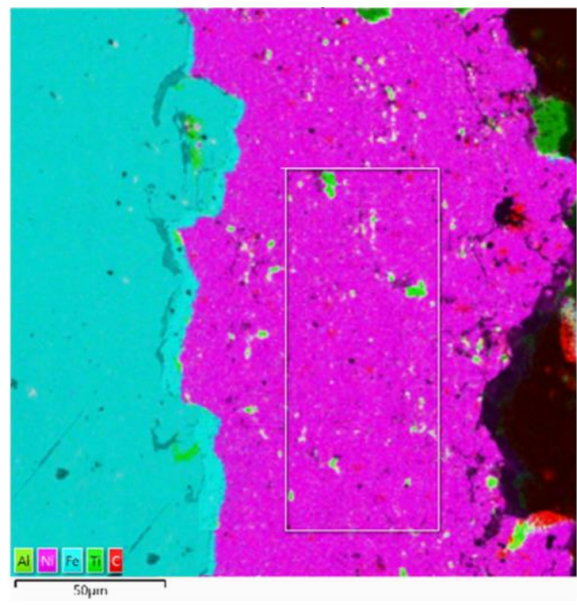

(a)

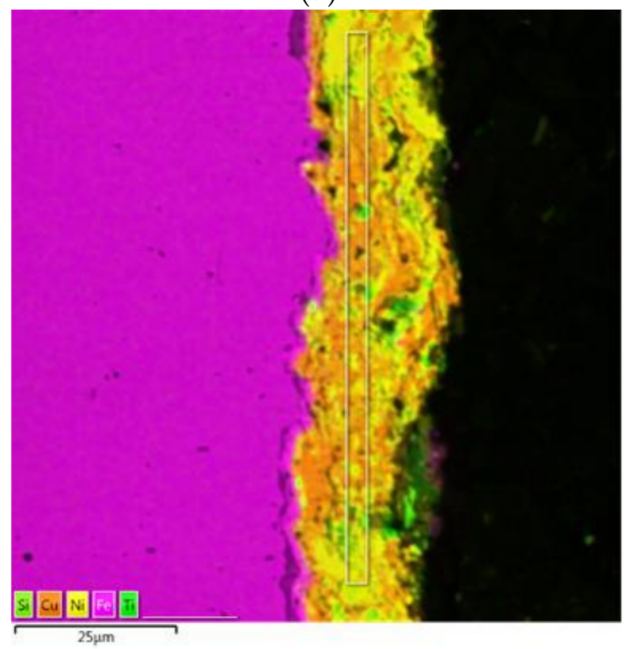

(c)

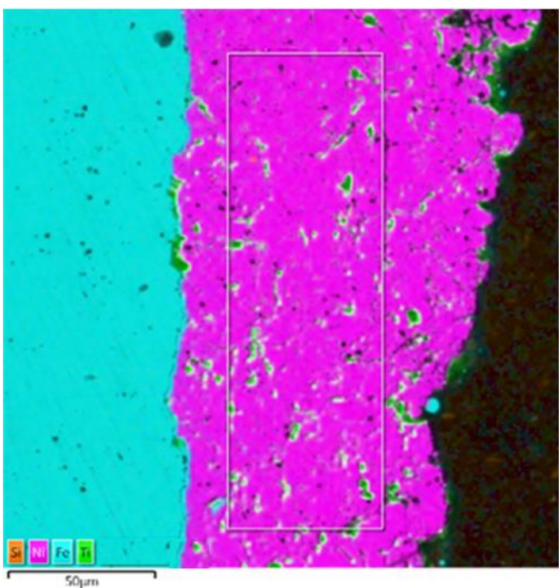

(b)

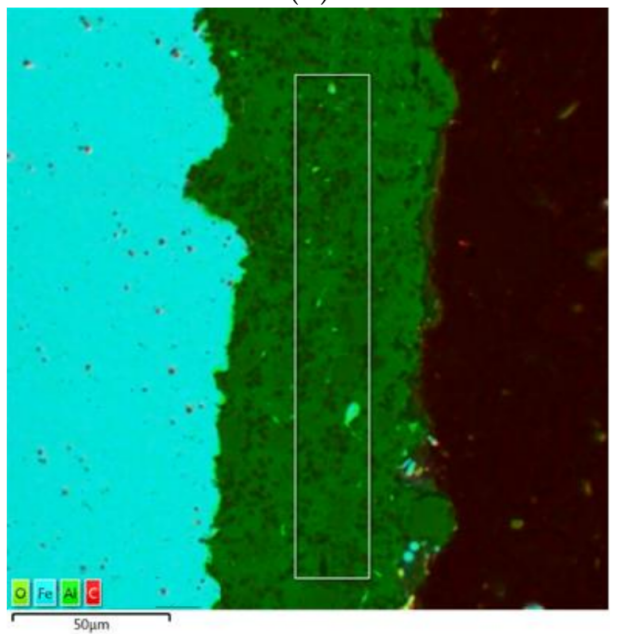

(d)

Figure 7. The nickel coatings with reinforcing particles: (a) Ni90-TiC10; (b) Ni60-TiC40; (c) (Ni50Cu50)60-TiC40 (MA)(Ni50-Cu50)60-TiC40 (MA); (d) $\mathrm{Ni}^{-} \mathrm{Al}_{2} \mathrm{O}_{3}$.

This may be a result of the powder particles, which are undertaking significant work. Hardening has occurred, and in addition, a large amount of oxygen has been absorbed by the powder surface.

It is important to note that when applying coatings made from mechanically alloyed powders, the coating is practically impossible to apply. This is because of the non-optimal deposition parameters [14]. This may additionally be due to the fact that as a result of the processing of the powder particles, significant work hardening was achieved; in addition, they collect a large amount of oxygen. To relieve stress and remove impurities, it is advisable to perform subsequent heat treatment of the powder. In this work, heat treatment was carried out in an oven in air and vacuum. With heat treatment in air, there was no that was not applied. Therefore, vacuum heat treatment was tested. With heat treatment in vacuum at a temperature of $\sim 360{ }^{\circ} \mathrm{C}$ for $1 \mathrm{~h}$, the NM50 (Ni50-Cu50)60-TiC40 (MA)(Ni50-Cu50)60-TiC40 (MA) powder was applied to the sample. The heat treatment mode (temperature and duration) was chosen as the optimal one in which impurities (e.g., volatile organic surfactants, etc.) were effectively removed. The coating thickness was 25-30 $\mu \mathrm{m}$. Nickel-copper powder without titanium carbide was practically not able to be applied. Nickel-zinc (MA) powder was also not able to be applied. It is necessary to investigate the modes of heat treatment in a vacuum. 
The porosity and microhardness of the different types of nickel-based coating, are shown in Table 2 depending on the chemical composition of the coatings (nickel-copper, nickel-zinc, nickel-reinforcing particles, pure nickel).

Table 2. The average values of porosity and microhardness of the studied types of coatings.

\begin{tabular}{ccc}
\hline Nickel Coating Type & Porosity, Unit/cm & Microhardness, HV \\
\hline $\mathrm{Ni}$ & 1.1 & 185 \\
$\mathrm{Ni}-\mathrm{TiC}$ & 1.1 & 90 \\
$\mathrm{Ni}-\mathrm{Al}_{2} \mathrm{O}_{3}$ & 0.5 & 130 \\
$\mathrm{Ni}-\mathrm{Cu}$ & 0.6 & 90 \\
$\mathrm{Ni}-\mathrm{Zn}$ & 2.1 & 170 \\
$\mathrm{Ni}-\mathrm{Cu}-\mathrm{TiC}(\mathrm{MA})$ & 1.2 & 100 \\
\hline
\end{tabular}

The study of the porosity of the coatings made of various initial powders showed that the porosity of the coatings is dependent on the composition of the powder material. The analysis of the obtained results shows that the matrix coating of pure nickel powder had a porosity of $0.5 \%$.

The most compact or dense specimens were $\mathrm{Ni}-\mathrm{Cu}$ and $\mathrm{Ni}-\mathrm{Al}_{2} \mathrm{O}_{3}$, with a porosity of 0.6 and 0.5 unit $/ \mathrm{cm}^{2}$, respectively. $\mathrm{Ni}, \mathrm{Ni}-\mathrm{TiC}, \mathrm{Ni}-\mathrm{Cu}-\mathrm{TiC}$ (MA) had a porosity of 1.1-1.2 unit $/ \mathrm{cm}^{2}$. The Ni-Zn specimen had the highest quantity of pores, with $2.1 \mathrm{unit} / \mathrm{cm}^{2}$.

$\mathrm{Ni}-\mathrm{Cu}$ and $\mathrm{Ni}-\mathrm{TiC}$ had the lowest microhardness value of $90 \mathrm{HV}$. Ni-Cu-TiC (MA) had an insignificantly higher microhardness of $100 \mathrm{HV}$. Ni and Ni-Zn had the highest value of microhardness, at 185 and $170 \mathrm{HV}$, respectively. A spread in microhardness was observed because of the locality of the method, with the size of the imprint being commensurate with powder particles.

\subsection{Characterization of Corrosion and Wear Properties}

The results of the evaluation of the influence of the coating thickness on the corrosion rate using electrochemical tests and resistance to hydroabrasive wear are shown in Figure 8.

As can be seen from Figure 8, the thickness of the coatings did not significantly affect the performance properties of the coatings, such as resistance to electrochemical corrosion and resistance to hydroabrasive action. Accordingly, further studies were performed for the samples of coatings with the most negligible thickness.

As can be seen from Figure 9, the samples of the Ni-Zn coating had the lowest corrosion resistance, with a corrosion rate under test conditions of $2.5 \pm 0.1 \mathrm{~mm} /$ year, which can be explained by the low corrosion resistance of zinc and its active dissolution under the test conditions, e.g., low $\mathrm{pH}$ and the presence of $\mathrm{Cl}^{-}$ions.

The corrosion resistance of the Ni-Zn samples was even lower than that for low-alloyed steel samples under the same conditions. However, zinc had a protective effect on the nickel matrix in operational conditions with higher $\mathrm{pH}$, meaning that these coatings can be successfully used.

The corrosion resistance of the pure Ni-coating (Ni100) was lower than the samples of the coatings with the addition of $\mathrm{Al}_{2} \mathrm{O}_{3}$, at 0.99 and $0.59 \mathrm{~mm} /$ year, respectively. The presence of the $\mathrm{Al}_{2} \mathrm{O}_{3}$ particles enhanced the corrosion resistance, which could be explained by the lower porosity of the samples. While the addition of the $\mathrm{TiC}$ particles did not increase the corrosion resistance of the coatings, this could be associated with the higher porosity of the samples. This assumption is based on weight loss measurements; an assessment of the coating degradation mechanism was not carried out.

The samples of the Ni-Cu coatings had the highest corrosion resistance. The corrosion rates were $0.9 \pm 0.1 \mathrm{~mm} /$ year, which could be associated with the high corrosion resistance of $\mathrm{Cu}$ and the low porosity of the samples. Meanwhile, the Ni-Cu-TiC samples, obtained by mechanical alloying, had significantly lower corrosion resistance, with corrosion rates of $1.67 \mathrm{~mm}$ /year, which could be explained by the high porosity. 


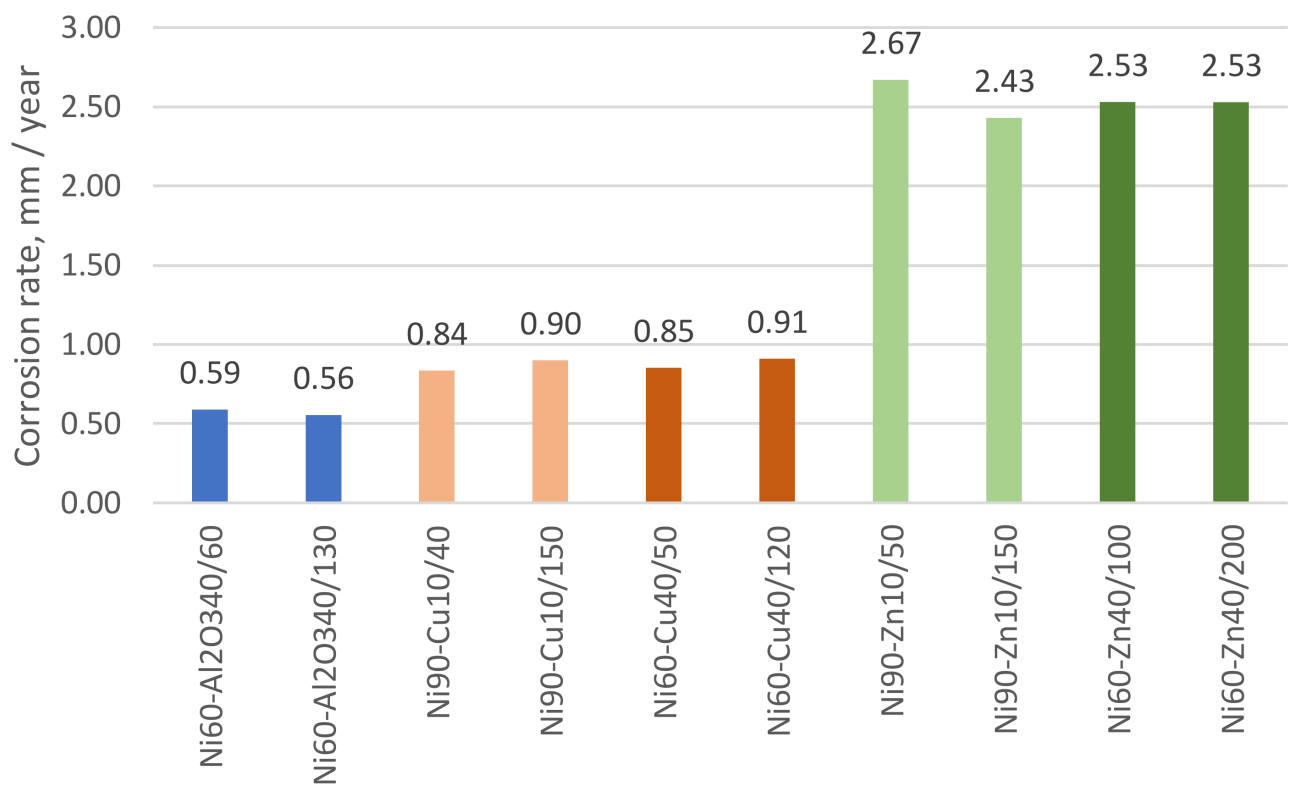

(a)

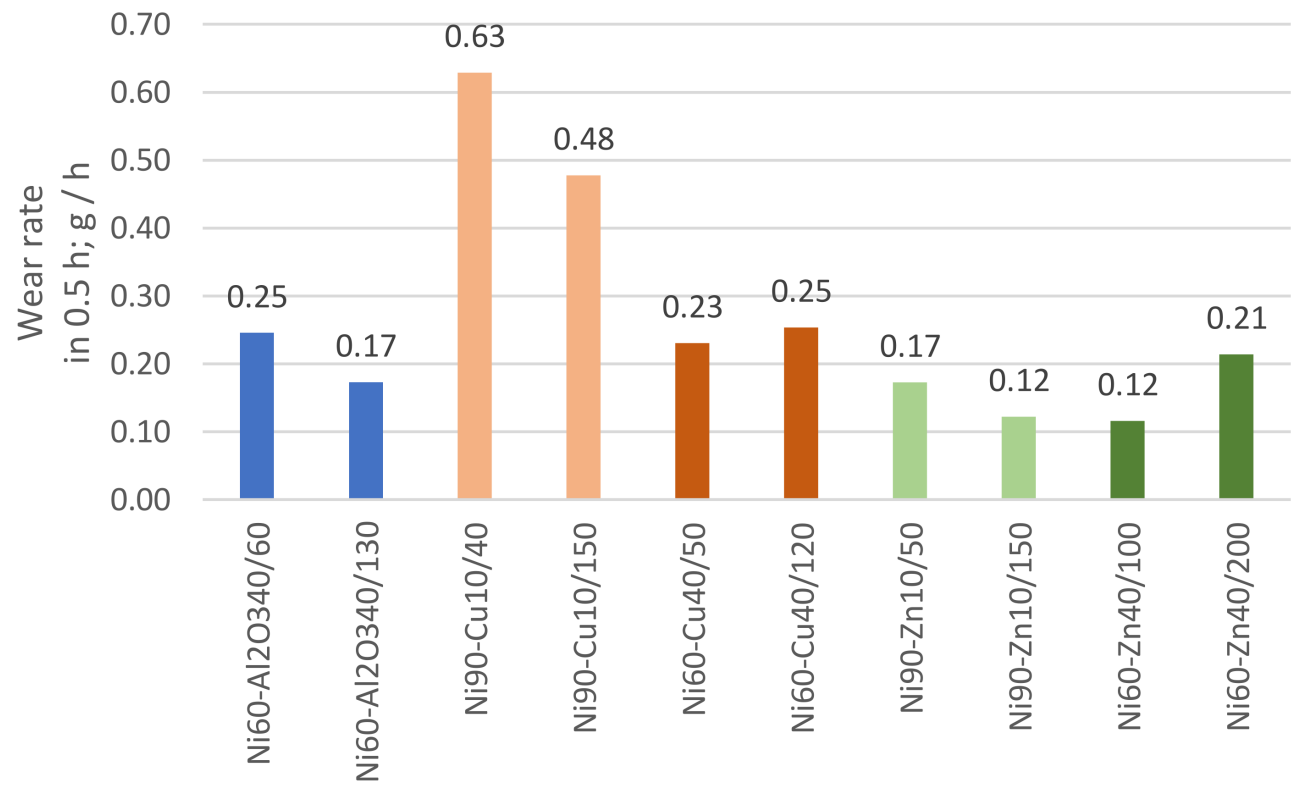

(b)

Figure 8. The influence of the coating thickness on (a) corrosion rate using electrochemical tests, and (b) resistance to hydroabrasive wear. 


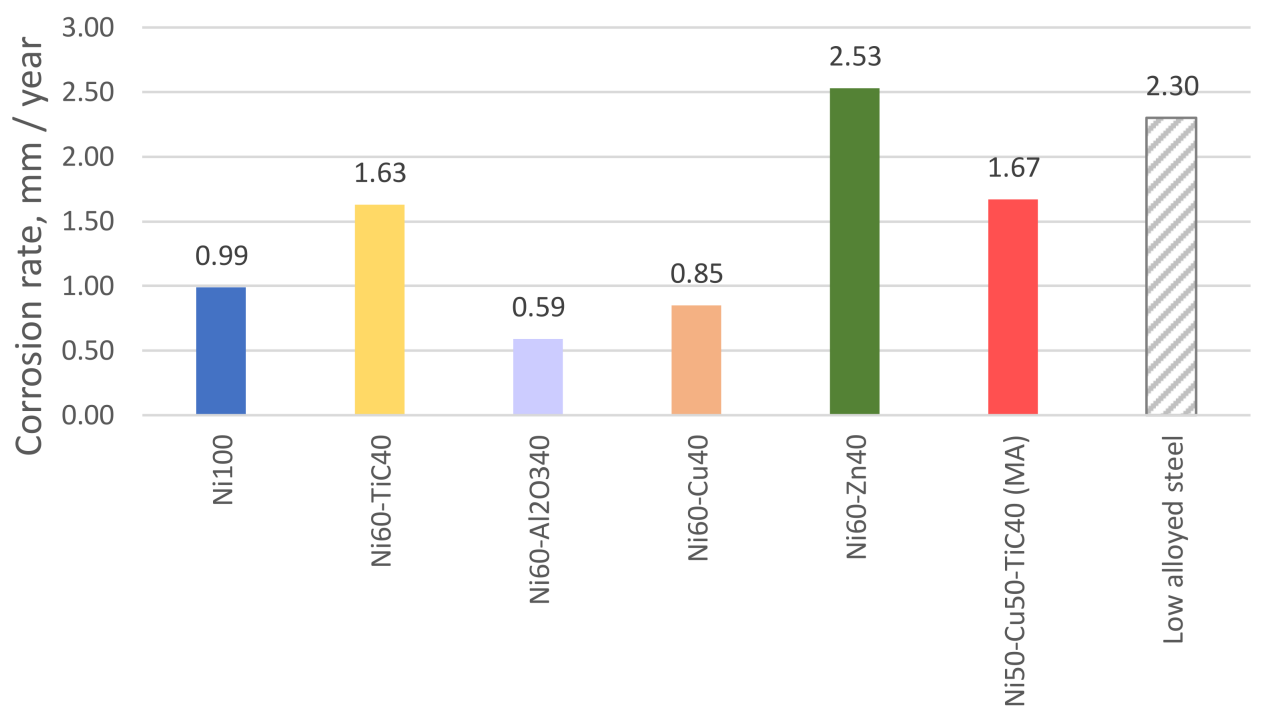

Figure 9. Corrosion rate (in mm per year) of the nickel coatings calculated using electrochemical tests in a $3 \% \mathrm{NaCl}$ solution with $\mathrm{pH}=2.5$ [37].

The results of corrosion testing in the simulated oil and gas media in the autoclave are given in Figure 10. The corrosion rate of the nickel coatings in the autoclave test in $5.0 \mathrm{wt} . \%$ $\mathrm{NaCl}$ solution saturated with hydrogen sulfide $\left(\mathrm{P}_{\mathrm{H} 2 \mathrm{~S}}=1 \mathrm{MPa}\right)$ and nitrogen $\left(\mathrm{P}_{\mathrm{N} 2}=5 \mathrm{MPa}\right)$ at a temperature of $+80^{\circ} \mathrm{C}$ with $\mathrm{pH}=3.5$.

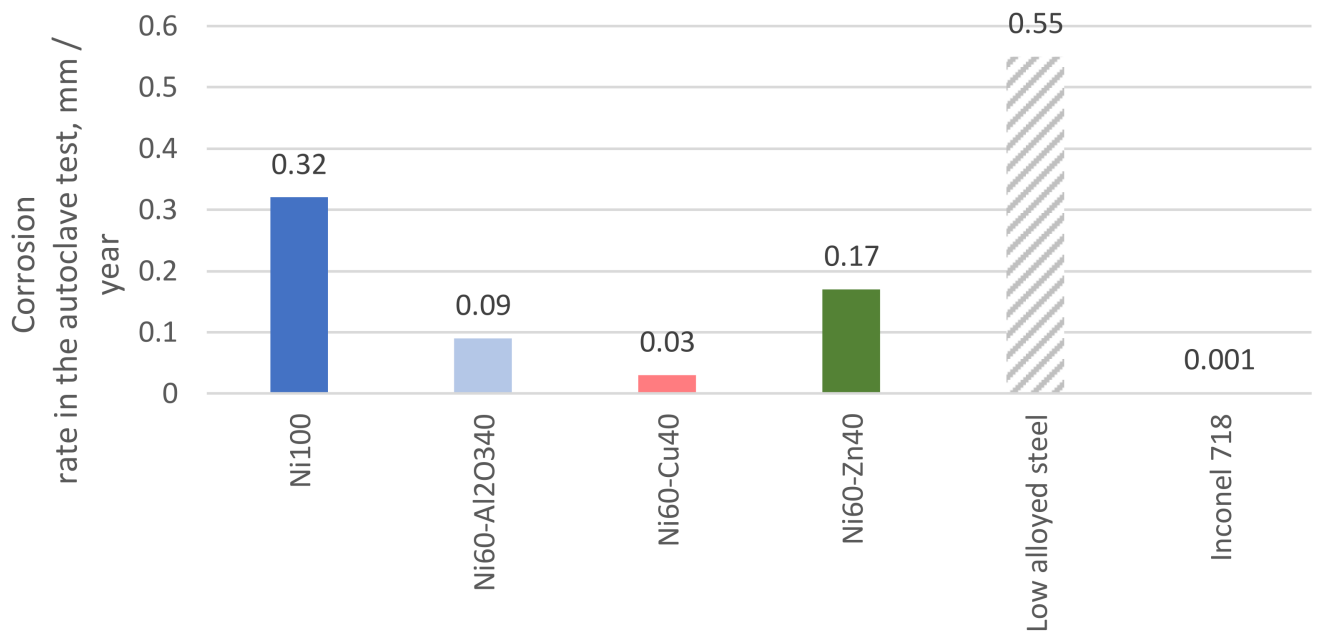

Figure 10. The corrosion rate of the nickel coatings in the autoclave test in $5.0 \mathrm{wt} . \% \mathrm{NaCl}$ solution saturated with hydrogen sulfide $\left(\mathrm{P}_{\mathrm{H} 2 \mathrm{~S}}=1 \mathrm{MPa}\right)$ and nitrogen $\left(\mathrm{P}_{\mathrm{N} 2}=5 \mathrm{MPa}\right)$ at a temperature of $+80{ }^{\circ} \mathrm{C}$ with $\mathrm{pH}=3.5$ [37].

According to the results of the autoclave tests, the $\mathrm{Ni}-\mathrm{Cu}$ samples demonstrated the highest corrosion resistance under the test conditions. The corrosion rate was about $0.03 \mathrm{~mm} /$ year. However, the samples of $\mathrm{Ni}-\mathrm{Al}_{2} \mathrm{O}_{3}$ and $\mathrm{Ni}-\mathrm{Zn}$ had higher corrosion rates of $0.09 \mathrm{~mm} /$ year and $0.17 \mathrm{~mm} /$ year, respectively. The pure nickel samples showed a lower corrosion resistance than all other samples, while in the electrochemical study, the same samples had the highest corrosion resistance. The corrosion resistance of the nickel coatings $\mathrm{Ni60}-\mathrm{Al}_{2} \mathrm{O}_{3} 40$ and $\mathrm{Ni60}-\mathrm{Cu} 40$ in conditions close to operational conditions (hydrogen sulfide-containing media) was less than $0.1 \mathrm{~mm} /$ year, that is, they can be recommended for deposits with a high content of hydrogen sulfide. The results of the autoclave tests 
demonstrated some inconsistency with the results of the electrochemical studies due to the level of the aggressive media, i.e., the presence of hydrogen sulfide and the increased temperature.

For comparison, the corrosion rate values for low-alloy steel and 718 nickel-based alloy are given in Figure 10. The corrosion rate of the nickel coatings in the autoclave test in 5.0 wt. $\% \mathrm{NaCl}$ solution saturated with hydrogen sulfide $\left(\mathrm{P}_{\mathrm{H} 2 \mathrm{~S}}=1 \mathrm{MPa}\right)$ and nitrogen $\left(\mathrm{P}_{\mathrm{N} 2}=5 \mathrm{MPa}\right)$ at a temperature of $+80{ }^{\circ} \mathrm{C}$ with $\mathrm{pH}=3.5$ It can be seen that the Ni-Cu samples have a higher corrosion rate by an order of magnitude compared to Inconel 718. It can also be seen that, compared with low-alloy steel, the studied nickel-based coatings provide significant corrosion protection: the corrosion rates with the coatings are 3 to 10 times lower.

Before and after autoclave testing, all the studied coatings were tested by means of the pull-off test to assess adhesion and degradation, Figure 11.

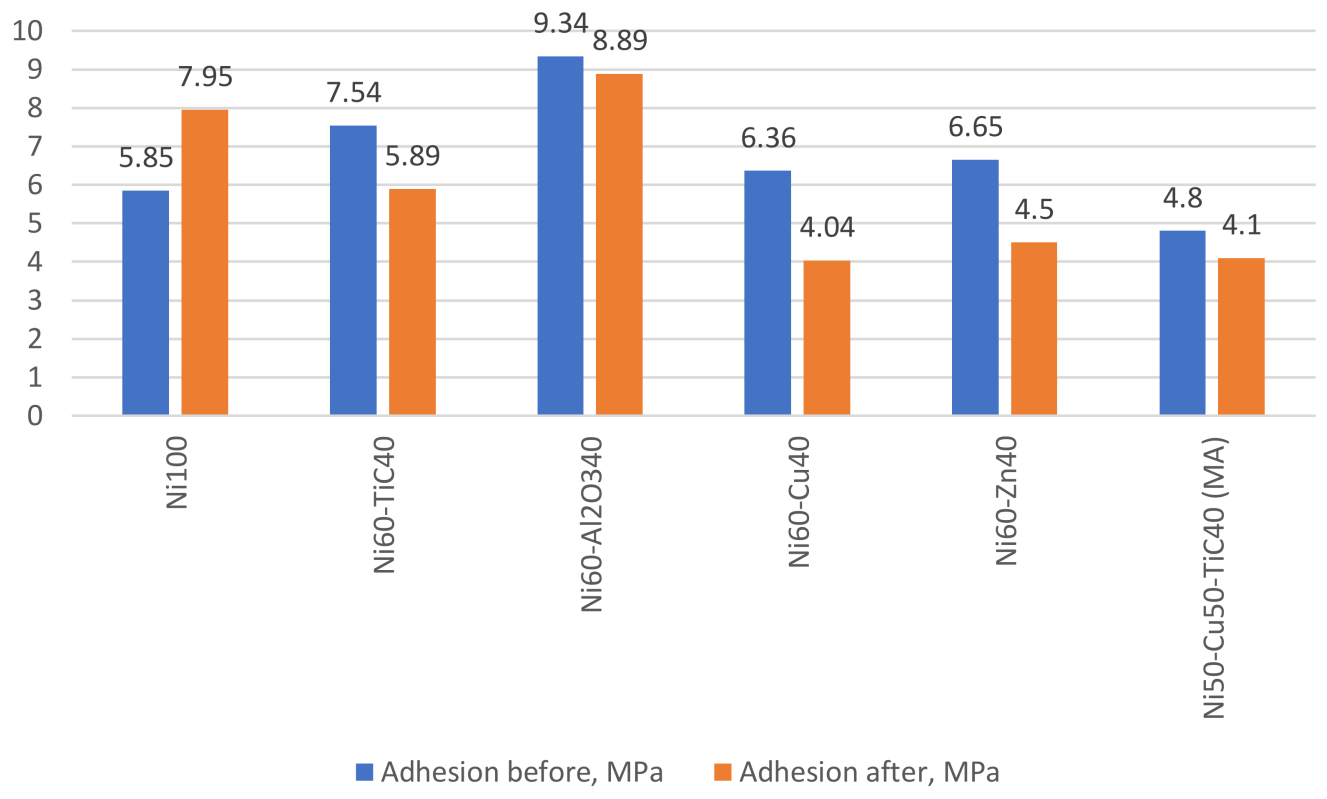

Figure 11. Adhesion strength values before and after the autoclave test.

All the samples had a sufficiently high adhesion before the autoclave corrosion tests (Figure 11) except the mechanically alloyed (Ni50-Cu50)60-TiC40 (MA) sample. The adhesion strength of the coating after the autoclave tests shows a decrease in adhesion by $20-40 \%$ compared to the initial values.

\subsection{Characterization of Wear Properties}

Figure 12 shows the results of hydroabrasive testing in an aqueous solution with $0.5 \mathrm{wt} \%$ quartz sand over 0.5 and $1 \mathrm{~h}$. The wear rate was estimated on the basis of the volume loss, since different coating compositions have different densities.

As can be seen from Figure 12, the microhardness (Table 2) values correlate with the wear resistance of the coatings. The highest resistance to hydroabrasive wear was exhibited by the $\mathrm{Ni}$ (microhardness of $185 \mathrm{HV}), \mathrm{Ni}-\mathrm{Zn}(170 \mathrm{HV})$, and $\mathrm{Ni}-\mathrm{Al}_{2} \mathrm{O}_{3}(130 \mathrm{HV})$ coatings. The Ni-TiC samples had the lowest resistance due to their lower hardness and the presence of discontinuities in the structures. The average volume losses for all investigated samples were $0.03 \mathrm{~cm}^{3} /\left(\mathrm{m}^{2} \cdot \mathrm{h}\right)$, except for the $\mathrm{Ni}$-TiC coatings. 


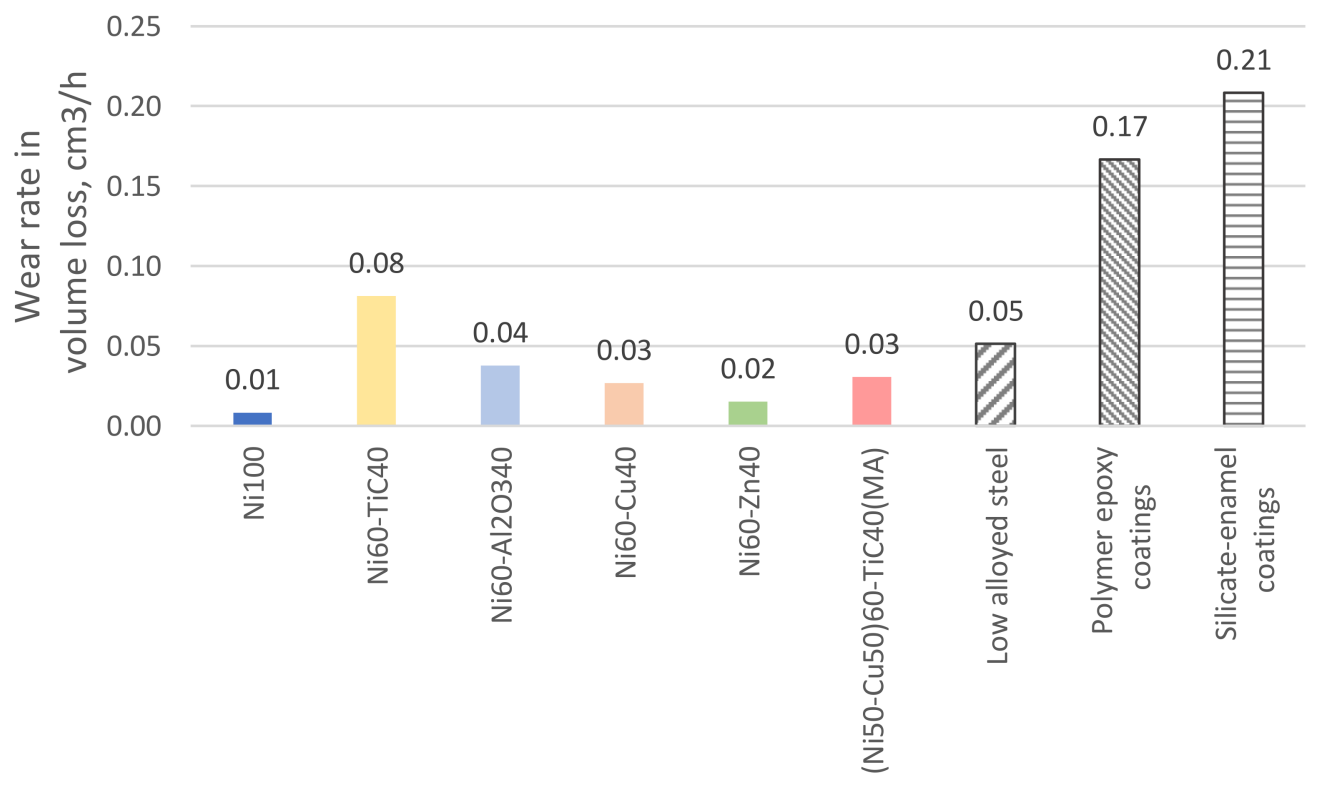

Figure 12. The rate of hydroabrasive wear of the coatings in volume loss for $0.5 \mathrm{~h}$.

The specimens with $\mathrm{Al}_{2} \mathrm{O}_{3}$ had low values of hydroabrasive wear and high corrosion resistance; the introduction of the $\mathrm{TiC}$ particles was not effective in improving these characteristics.

It is worth noting that according to [26], the hydroabrasive wear rates of industrial coatings used for pipelines are $0.17 \mathrm{~cm}^{3} /\left(\mathrm{m}^{2} \cdot \mathrm{h}\right)$, on average, for coatings on a polymer epoxy base; $0.2 \mathrm{~cm}^{3} /\left(\mathrm{m}^{2} \cdot \mathrm{h}\right)$ for coatings on a silicate-enamel base; and low-alloyed steel pipelines without any coatings have a wear rate of $0.05 \mathrm{~cm}^{3} /\left(\mathrm{m}^{2} \cdot \mathrm{h}\right)$. Thus, the results of tests for resistance to hydroabrasive wear show that nickel-based coatings are more resistant than the well-known non-metallic coatings used in industry, and they can be recommended for use in situations with high mechanical particle contents.

According to the corrosion and hydroabrasive tests, the increase in thickness does not improve the properties, so a thickness of 40 microns is sufficient to protect against corrosion and wear.

\section{Summary}

1. It was shown that the coating based on $\mathrm{Ni}-\mathrm{Zn}$ had the lowest corrosion characteristics (under simulated oilfield conditions, the corrosion rate was $0.17-0.2 \mathrm{~mm} /$ year). Despite these coatings having the highest wear resistance characteristics, the protective effect of zinc allows them to be used as corrosion-resistant material, while at the same time being economically attractive.

2. The nickel-copper coating samples had high corrosion resistance, but low wear resistance, due to their low hardness. Applying coatings of mechanically alloyed nickel-copper powders is practically impossible without titanium carbide.

3. The nickel samples had low corrosion resistance, but high resistance to hydroabrasive wear.

4. Nickel coatings can be recommended for use in deposits with a high content of mechanical particles in the fluid, as they are highly resistant to hydroabrasive wear.

5. The corrosion resistance of the nickel coatings Ni60- $\mathrm{Al}_{2} \mathrm{O}_{3} 40$ and Ni60-Cu40 under conditions close to operational conditions was less than $0.1 \mathrm{~mm} /$ year, so they can be recommended for deposits with a high content of hydrogen sulfide.

6. All the studied coating specimens had a sufficiently high adhesion before and after testing in the autoclave.

7. A thickness of 40-60 microns provided acceptable performance in the studied coatings. 
8. The studied nickel coatings had higher wear characteristics than well-known epoxy and silicate enamel coatings.

\section{Conclusions}

In this study, the samples of the nickel-based $\mathrm{Ni}-\mathrm{Zn}, \mathrm{Ni}-\mathrm{Cu}, \mathrm{Ni}-\mathrm{Al}_{2} \mathrm{O}_{3}, \mathrm{Ni}-\mathrm{TiC}, \mathrm{Ni}$ fabricated using cold gas dynamic spraying were assessed to determine their applicability in the oil and gas industry.

It was shown that the use of technology to obtain functional coatings by cold gas dynamic spraying makes it possible to achieve a wide range of applied powders (including composite ones with reinforced particles) with various element ratios and a wide range of thicknesses. Varying the chemical composition and the thickness of the coating makes it possible to obtain optimal qualities, as well as the necessary properties, in Ni-based coatings for use in the oil and gas industry made by cold gas spraying.

On the basis of the experimental studies carried out in this work, nickel coatings based on Ni60- $\mathrm{Al}_{2} \mathrm{O}_{3} 40$ and Ni60-Cu with a thickness of about 40-60 microns could be relevant for use in acidic environments such as in the presence of chloride ions or hydrogen sulfide, and can also sustain being subjected to abrasive particles. In such media, $\mathrm{Ni}$ and $\mathrm{Ni}-\mathrm{Zn}$ may not be equally effective. Nevertheless, all of the studied nickel coatings could be implemented in oil wells requiring high abrasive wear resistance, where epoxy and silica-enamel coatings do not meet the requirements.

The technology of spraying composite powders that has been developed and mastered is very promising for the performance of urgent tasks in the oil and gas industry, especially in terms of local repair in the field, but it could also be implemented for the production of new parts or equipment components.

Author Contributions: Conceptualization, methodology, formal analysis, E.A. and M.S.; investigation, D.S.; resources, data curation, P.G.; writing—original draft preparation, writing—review and editing, E.A., M.S. and D.G.; supervision, project administration, funding acquisition, N.S. All authors have read and agreed to the published version of the manuscript.

Funding: This research was partially funded by the Ministry of Science and Higher Education of the Russian Federation as part of World-Class Research Center program: Advanced Digital Technologies (contract No. 075-15-2020-934 dated 17 November 2020).

Institutional Review Board Statement: Not applicable.

Informed Consent Statement: Not applicable.

Data Availability Statement: Not applicable.

Conflicts of Interest: The authors declare no conflict of interest.

\section{References}

1. Heidersbach, R. Metallurgy and Corrosion Control in Oil and Gas Production, 2nd ed.; Wiley Series in Corrosion; John Wiley \& Sons: Hoboken, NJ, USA, 2011; 293p, ISBN 13:9780470248485.

2. Craig, B.D. Oilfield Metallurgy and Corrosion, 3rd ed.; MetCorr: Denver, CO, USA, 2014; 335p, ISBN 0615961355.

3. Popoola, L.T.; Grema, A.S.; Latinwo, G.K.; Gutti, B.; Balogun, A.S. Corrosion problems during oil and gas production and its mitigation. Int. J. Ind. Chem. 2013, 4, 35. [CrossRef]

4. Rebak, R.B. Pitting Characteristics of Nickel Alloys-A Review. In Corrosion Conference Proceedings; NACE: Houston, TX, USA, 2016; 7450p.

5. MacLean, M.; Farhat, Z.; Jarjoura, G.; Fayyad, E.; Abdullah, A.; Hassan, M. Fabrication and investigation of the scratch and indentation behavior of new generation Ni-P-nano-NiTi composite coating for oil and gas pipelines. Wear 2019, 426-427, 265-276. [CrossRef]

6. Wang, C.; Farhat, Z.; Jarjoura, G.; Hassan, M.K.; Abdullah, A.M. Indentation and erosion behavior of electroless Ni-P coating on pipeline steel. Wear 2017, 376-377, 1630-1639. [CrossRef]

7. Kumar, P.; Siva, N. Shanmugam Some studies on nickel-based Inconel 625 hard overlays on AISI 316L plate by gas metal arc welding based hardfacing process. Wear 2020, 456-457, 203394. [CrossRef]

8. Sahoo, C.K.; Masanta, M. Microstructure and mechanical properties of TiC-Ni coating on AISI304 steel produced by TIG cladding process. J. Mater. Processing Technol. 2017, 240, 126-137. [CrossRef] 
9. Pawlowski, L. The Science and Engineering of Thermal Spray Coatings, 2nd ed.; John Wiley \& Sons Ltd.: Hoboken, NJ, USA, 2008. [CrossRef]

10. Brandolt, C.S.; Vega, O.; Menezes, M.R.; Schroeder, T.L.; Malfatti, C.F. Corrosion behavior of nickel and cobalt coatings obtained by high-velocity oxy-fuel (HVOF) thermal spraying on API 5CT P110 steel. Mater. Corros. 2016, 67, 368-377. [CrossRef]

11. Ermakov, B.S.; Alkhimenko, A.A.; Shaposhnikov, N.O.; Ermakov, S.B.; Shatsky, T.E.; Igolkin, A.F. The Use of Sprayed Powders to Create Coatings in the Welds of Oilfield Pipelines. In Proceedings of the IOP Conference Series: Materials Science and Engineering, Chennai, India, 16-17 September 2020; Volume 826. [CrossRef]

12. Brissonneau, L.; Vahlas, C. Precursors and operating conditions for the metal-organic chemical vapor deposition of nickel films Ann. Chim. Sci. Matériaux 2000, 25, 81-90. [CrossRef]

13. Bowden, C.; Matthews, A. A study of the corrosion properties of PVD Zn-Ni coatings. Surf. Coat. Technol. 1995, 76-77, 508-515. [CrossRef]

14. Geraschenkov, D.A.; Vasiliev, A.F.; Farmakovsky, B.V.; Mashek, A.C.H. Study of the flow temperature in the process of cold gas-dynamic spraying of functional coatings. Mater. Sci. 2014, 1, 87-96.

15. Gerashchenkov, D.A.; Bobkova, T.I.; Vasiliev, A.F.; Kuznetsov, P.A.; Samodelkin, E.A.; Farmakovsky, B.V. Functional protective coatings of nickel-based alloys. Vopr. Materialoved. 2018, 1, 110-114. (In Russian) [CrossRef]

16. Alkhimov, A.P.; Klinkov, S.V.; Kosarev, V.F. Investigation of heat transfer of a supersonic plane jet with an obstacle under conditions of gas-dynamic spraying. Therm. Phys. Aeromech. 2000, 7, 389-396.

17. Parmar, H.; Tucci, F.; Carlone, P.; Sudarshan, T.S. Metallisation of polymers and polymer matrix composites by cold spray: State of the art and research perspectives. Int. Mater. Rev. 2021, 66, 1-24. [CrossRef]

18. Kumar, S.; Kumar, M.; Jindal, N. Overview of cold spray coatings applications and comparisons: A critical review. World J. Eng. 2020, 17, 27-51. [CrossRef]

19. Meng, M.; Leech, A.; Le, H. Mechanical properties and tribological behavior of electroless Ni-P-Cu coatings on corrosion-resistant alloys under ultrahigh contact stress with sprayed nanoparticles. Tribol. Int. 2019, 139, 59-66. [CrossRef]

20. Li, B.; Mei, T.; Li, D.; Du, S.; Zhang, W. Structural and corrosion behavior of Ni-Cu and Ni-Cu/ZrO 2 composite coating electrodeposited from sulphate-citrate bath at low $\mathrm{Cu}$ concentration with additives. J. Alloys Compd. 2019, 804, 192-201. [CrossRef]

21. Hammami, O. Influence of $\mathrm{Zn}-\mathrm{Ni}$ alloy electrodeposition techniques on the coating corrosion behavior in chloride solution. Surf. Coat. Technol. 2009, 203, 2863-2870. [CrossRef]

22. Shourgeshty, M.; Aliofkhazraei, M.; Karimzadeh, A.; Poursalehi, R. Corrosion and wear properties of $\mathrm{Zn}-\mathrm{Ni}$ and $\mathrm{Zn}-\mathrm{Ni}-\mathrm{Al}_{2} \mathrm{O}_{3}$ multilayer electrodeposited coatings. Mater. Res. Express 2017, 4, 096406. [CrossRef]

23. Oryshchenko, A.S.; Gerashchenkov, D.A. Aluminum matrix functional coatings with high microhardness on the basis of Al-Sn + $\mathrm{Al}_{2} \mathrm{O}_{3}$ composite powders fabricated by cold gas dynamic spraying. Inorg. Mater. Appl. Res. 2016, 7, 863-867. [CrossRef]

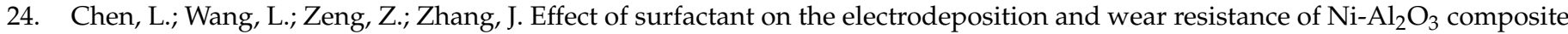
coatings. Mater. Sci. Eng. A 2006, 434, 319-325. [CrossRef]

25. Szczygieł, B.; Kołodziej, M. Corrosion resistance of $\mathrm{Ni} / \mathrm{Al}_{2} \mathrm{O}_{3}$ coatings in $\mathrm{NaCl}$ solution. Trans. Inst. Met. Finish 2005, 83, 181-187. [CrossRef]

26. Ghaziof, S.; Kilmartin, P.; Gao, W. Electrochemical studies of sol-enhanced $\mathrm{Zn}-\mathrm{Ni}-\mathrm{Al}_{2} \mathrm{O}_{3}$ composite and $\mathrm{Zn}-\mathrm{Ni}$ alloy coatings J. Electroanal. Chem. 2015, 755, 63-70. [CrossRef]

27. Baghery, P.; Farzam, M.; Mousavi, A.B.; Hosseini, M. Ni-TiO 2 nanocomposite coating with high resistance to corrosion and wear. Surf. Coat. Technol. 2010, 204, 3804-3810. [CrossRef]

28. Zimmerman, A. Pulse electrodeposition of Ni-SiC nanocomposite. Mater. Lett. 2002, 52, 85-90. [CrossRef]

29. Tao, Y.; Xiong, T.; Sun, C.; Jin, H.; Du, H.; Li, T. Effect of $\alpha-\mathrm{Al}_{2} \mathrm{O}_{3}$ on the properties of cold sprayed $\mathrm{Al} / \alpha-\mathrm{Al}_{2} \mathrm{O}_{3}$ composite coatings on AZ91D magnesium alloy. Appl. Surf. Sci. 2009, 256, 261-266. [CrossRef]

30. Lee, Y.; Jung, A.H.; Lee, S.Y.; You, Y.H.; Ko, K.H. Correlation between $\mathrm{Al}_{2} \mathrm{O}_{3}$ particles and interface of $\mathrm{Al}_{-}-\mathrm{Al}_{2} \mathrm{O}_{3}$ coatings by cold spray. Appl. Surf. Sci. 2009, 205, 1891-1898. [CrossRef]

31. Mondol, D.P.; Das, S.; Jha, A.K.; Yegneswaren, A.H. Abrasive wear of $\mathrm{Al}$ alloy- $\mathrm{Al}_{2} \mathrm{O}_{3}$ particle composite: A study on the combined effect of load and size abrasive. Wear 1998, 233, 131-138. [CrossRef]

32. Hodder, K.J.; Izadi, H.; McDonald, A.G.; Gerlich, A.P. Fabrication of aluminum-alumina metal matrix composites via cold gas dynamic spraying at low pressure followed by friction stir processing. Mater. Sci. Eng. 2012, 556, 114-121. [CrossRef]

33. Alekseeva, E.; Shishkova, M.; Strekalovskaya, D.; Gerashchenkov, D. Ni-Based Coatings for Oil and Gas Industry Fabricated by Cold Gas Spraying. Mater. Proc. 2021, 3, 2. [CrossRef]

34. Lashkov, B.A. On the experimental determination of the coefficients of recovery of the velocity of the particles of the gas suspension flow upon impact on the surface. Eng. Phys. J. 1991, 60, 197-203. [CrossRef]

35. ASTM G3-14; Standard Practice for Conventions Applicable to Electrochemical Measurements in Corrosion Testing. ASTM International: Pennsylvania, PA, USA, 2019. [CrossRef]

36. Kovalev, M.; Alekseeva, E.; Shaposhnikov, N. Investigation of hydroabrasive resistance of internal anti-corrosion coatings used in the oil and gas industry. IOP Conference Series: Materials Science and Engineering. Int. Sci. Pract. Conf. Mater. Sci. 2020, 889, 012020.

37. Alekseeva, E.; Galata, L.; Lapechenkov, A.; Kovalev, M. Evaluation of Corrosion Resistance of Nickel-based Alloy EP718 for use in Hydrogen Sulphide Containing Environment. In Proceedings of the E3S Web of Conferences, Corrosion in the Oil \& Gas Industry, Saint-Petersburg, Russia, 14-16 December 2020; Volume 225, p. 03001. [CrossRef] 